Check for updates

Cite this: RSC Adv., 2018, 8, 22

Received 16th October 2017

Accepted 12th December 2017

DOI: $10.1039 / c 7 r a 11427 c$

rsc.li/rsc-advances

\section{A copper-manganese composite oxide as QCM sensing layers for detection of formaldehyde gas}

\begin{abstract}
Mingqing Yang and Junhui He (D)*
A copper-manganese composite oxide was synthesized by controlling the molar ratio of $\mathrm{Cu}$ to $\mathrm{Mn}$ and calcination temperature. Scanning electron microscopy, transmission electron microscopy, X-ray diffraction, and nitrogen adsorption-desorption measurements were employed to characterize the obtained products. The as-prepared copper-manganese composite oxide functionalized QCM resonators were fabricated and explored for $\mathrm{HCHO}$ sensing. The copper-manganese composite oxide functionalized QCM resonators had a significant response to $\mathrm{HCHO}$, and the sensitivity of the resonators reached $6.35 \mathrm{~Hz}(\mu \mathrm{g} \mathrm{ppm})^{-1}$. Neither the response nor the sensing profile observed significant changes after 60 days. The linear equation between the response of the QCM resonator and $\mathrm{HCHO}$ concentration endows the copper-manganese composite oxide functionalized QCM resonators with a capability of $\mathrm{HCHO}$ quantitative analysis. The adsorption-desorption process via hydrogen bonding between the oxygen of the copper-manganese composite oxide and $\mathrm{HCHO}$ molecules may be a plausible sensing mechanism for $\mathrm{HCHO}$ sensing.
\end{abstract}

\section{Introduction}

Formaldehyde (HCHO) emits from widely used building and decorative materials, oil paints and textiles. It is one of the most dominant and best-known air pollutants in an indoor environment. HCHO can cause irritation to the eyes, nose, and throat, even at low levels for short periods. Longer exposure or a higher dose can cause coughing, choking, nasopharyngeal cancer and leukemia. Severe exposure can cause death from throat swelling or from chemical burns to the lungs. ${ }^{1,2}$ Therefore, it is important and highly desired to detect any possible presence of HCHO. Actually, many techniques have been utilized to detect HCHO gas, such as UV-VIS spectrophotometry, gas chromatography-mass spectrometry and high-performance liquid chromatography. However, these instrumental analysis methods are generally costly, time-consuming and cannot be used for on-site detection. Some chemical sensors, potentiometric sensors, electrochemical sensors and piezoelectric sensors have also been used to detect $\mathrm{HCHO}$ gas. ${ }^{3-10}$ Until now, it has still been challenging to determine $\mathrm{HCHO}$ on-site in a real time manner with high sensing properties, such as fast response, high sensitivity, good reproducibility and stability.

Quartz crystal microbalance (QCM) could measure nanogramorder changes in mass loading on the quartz crystal surface by observation of frequency shift based on the Sauerbrey equation.

Functional Nanomaterials Laboratory, Center for Micro/Nanomaterials and Technology, Key Laboratory of Photochemical Conversion and Optoelectronic Materials, Technical Institute of Physics and Chemistry, Chinese Academy of Sciences (CAS), 29 Zhongguancun East Road, Haidian District, Beijing 100190, China. E-mail:jhhe@mail.ipc.ac.cn; Tel: +861082543535
QCM has attracted considerable interest in the area of chemical sensing because of its many advantages such as low cost, easy installation and inherent ability to monitor analytes in situ and real time. ${ }^{11-18}$ Thus far, how to modify resonator surface properties becomes an essential issue for enhancing the range of application of QCM sensors. Recently, nanostructured composite metal oxides, which have different constituent parts, oxidation states and coordination numbers, are especially interesting due to their unique thermal, optical, electronic, photonic, catalytic and sensing properties. ${ }^{19-24}$ Among them, copper-manganese composite oxide is interesting and was exploited for application as catalyst (Hopcalite) for the conversion of carbon monoxide to carbon dioxide. Hopcalite catalysts are also used to remove ethylene oxide and other VOCs. The active sites of coppermanganese composite oxide could adsorb and catalyze vaporized molecules at room temperature. In fact, copper-manganese composite oxide has been extensively studied as catalyst. There are very limited studies using copper-manganese composite oxide as sensing material. To our best knowledge, however, coppermanganese composite oxide has not yet been explored so far as sensing media on QCM for detection of HCHO. In the current work, we synthesized copper-manganese composite oxide, from which copper-manganese composite oxide functionalized QCM resonators were fabricated and explored for HCHO sensing.

\section{Experimental}

\subsection{Materials}

Copper nitrate, manganese acetate and absolute ethanol were purchased from Beijing Chemical Works. All chemicals were 
analytic grade, and were used without further purification. Ultrapure water with a resistivity higher than $18.2 \mathrm{M} \Omega \mathrm{cm}$ was used in all experiments and obtained from a three-stage Millipore Mill-Q purification system.

\subsection{Preparation and characterization of copper-manganese composite oxide}

In a typical preparation, $0.49 \mathrm{~g}$ of $\mathrm{Mn}\left(\mathrm{CH}_{3} \mathrm{COO}\right)_{2} \cdot 4 \mathrm{H}_{2} \mathrm{O}, 0.32 \mathrm{~g}$ of $\mathrm{KMnO}_{4}$ and $0.24 \mathrm{~g}$ of $\mathrm{Cu}\left(\mathrm{NO}_{3}\right)_{2} \cdot 3 \mathrm{H}_{2} \mathrm{O}$ were first dissolved in three volumes of pure water $(20 \mathrm{~mL})$, respectively. Then the aqueous $\mathrm{KMnO}_{4}$ was slowly added into the aqueous $\mathrm{Mn}\left(\mathrm{CH}_{3} \mathrm{COO}\right)_{2}$ under vigorous stirring at room temperature, followed by addition of the aqueous $\mathrm{Cu}\left(\mathrm{NO}_{3}\right)_{2}$ into the above solution. The molar ratio of $\mathrm{Cu}^{2+}$ to $\mathrm{Mn}^{2+}$ was controlled at $1: 2$. The mixture was continually stirred for $24 \mathrm{~h}$, and then incubated for $2 \mathrm{~h}$. The precipitate was isolated by centrifugation, and washed many times with pure water and absolute ethanol. Then the obtained sample was dried at $60{ }^{\circ} \mathrm{C}$ for $24 \mathrm{~h}$. Finally, the sample was calcinated at $300{ }^{\circ} \mathrm{C}$ for $3 \mathrm{~h}$, and a black powder product was collected.

X-ray diffraction (XRD) patterns of copper-manganese composite oxide powders were recorded on a Bruker D8 Focus $\mathrm{X}$-ray diffractometer (Germany) using $\mathrm{Cu} \mathrm{K} \alpha$ radiation $(\lambda=$ $0.1542 \mathrm{~nm}$ ) operated at $40 \mathrm{kV}$ and $40 \mathrm{~mA}$. The specific surface areas of copper-manganese composite oxide products were determined by nitrogen adsorption-desorption measurements on a QuadraSorb SI automated surface area and pore size analyzer (Quantachrome Instruments, USA). Scanning electron microscopy (SEM) observations were carried out on a Hitachi S-4800 field emission scanning electron microscope (Japan). Transmission electron microscopy (TEM) observations were performed on a JEOL 2100 transmission electron microscope at an acceleration voltage of $200 \mathrm{kV}$ (Japan).

\subsection{Fabrication and measurement of QCM resonators}

A drop-coating method was used to coat both sides $(5 \mathrm{~mm}$ in diameter) of a silver-coated QCM resonator (9 $\mathrm{MHz}$, AT-cut piezoelectric quartz crystal, Beijing Chenjing Electronics Co., China). In a typical procedure, $4 \mathrm{mg}$ of the as-prepared coppermanganese composite oxide was dispersed homogeneously in $2 \mathrm{~mL}$ pure water, and $7 \mu \mathrm{L}$ of the obtained suspension was dropped onto the surface of silver electrode by using a microsyringe. The QCM resonators with copper-manganese composite oxide thin films were quickly dried at $60{ }^{\circ} \mathrm{C}$.

Sensing properties were examined by placing coppermanganese composite oxide functionalized QCM resonators in a glass chamber inside of an incubator where temperature $\left(20{ }^{\circ} \mathrm{C}\right)$ and relative humidity were accurately controlled by drying tower (activated carbons and molecular sieves). A dynamic gas-mixing apparatus was used to steadily generate gas containing HCHO of low concentration. The gas concentration was controlled by regulating the gas flow through mass flow controllers. A four-way valve was applied to switch between air flow and diluted HCHO flow. Frequency shifts were recorded by an Agilent 53131A universal counter linked to a computer.

\section{Results and discussion}

\subsection{Characterization of copper-manganese composite oxide}

The morphological structures of as-prepared products were investigated by using SEM and TEM (Fig. 1). Clearly, the asprepared copper-manganese composite oxide consists of aggregates of nanoparticles. The phase analysis of as-prepared product was carried out by XRD. As shown in Fig. 2a, the asprepared copper-manganese composite oxide was amorphous. Nitrogen physisorption represents the most widely used technique to measure catalyst surface area. By nitrogen adsorption-desorption measurement (Fig. 2b), the specific surface areas of as-prepared copper-manganese composite oxide was measured to be $150 \mathrm{~m}^{2} \mathrm{~g}^{-1}$.

\subsection{Sensing properties of copper-manganese composite oxide functionalized QCM resonators}

The sensing performance of copper-manganese composite oxide functionalized QCM resonators were examined by placing them in a glass chamber, and the concentration of HCHO was controlled at 0.3-1.7 ppm. An unmodified silver-coated QCM resonator was also tested as control for comparison (Fig. 3). While the red solid arrow indicates the time at which air containing 1.7 ppm HCHO was introduced into the testing chamber, the blue dashed arrow indicates the time at which air started to flush the testing chamber. Clearly, the unmodified silver-coated QCM resonator had no response to HCHO. Fig. 4 shows a response curve of a copper-manganese composite oxide functionalized QCM resonator under otherwise identical conditions. The coating amount on QCM resonator was $25 \mu \mathrm{g}$ according to the Sauerbrey equation. Compared with the unmodified silver-coated QCM resonator, the copper-manganese composite oxide functionalized QCM resonator had a significant response to $\mathrm{HCHO}$ of $1.7 \mathrm{ppm}$. When air containing 1.7 ppm HCHO was introduced into the testing chamber, the QCM frequency began to decrease. The frequency shift initially decreased rapidly, reaching $-270 \mathrm{~Hz}$ in $60 \mathrm{~s}$. Then, the frequency shift decreased less rapidly, reaching $-355 \mathrm{~Hz}$ at equilibrium state. The sensitivity of sensing film functionalized QCM resonator is assessed by the ratio of (frequency shift at $60 \mathrm{~s}$ of $\mathrm{HCHO}$ exposure)/(coating amount)/(HCHO concentration). And the sensitivity of copper-manganese composite oxide functionalized QCM resonator is $6.35 \mathrm{~Hz}(\mu \mathrm{g} \mathrm{ppm})^{-1}$, which is ca. 3 times as high as that of graphene oxide functionalized

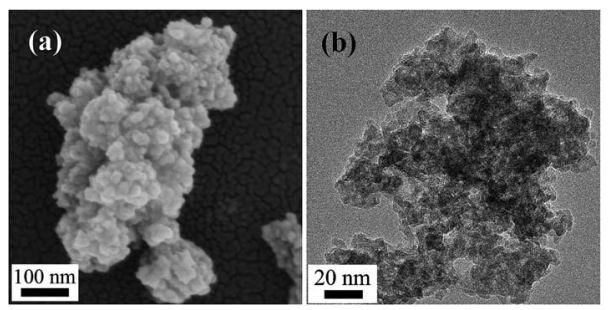

Fig. 1 SEM (a) and TEM (b) images of as-prepared copper-manganese composite oxide. 

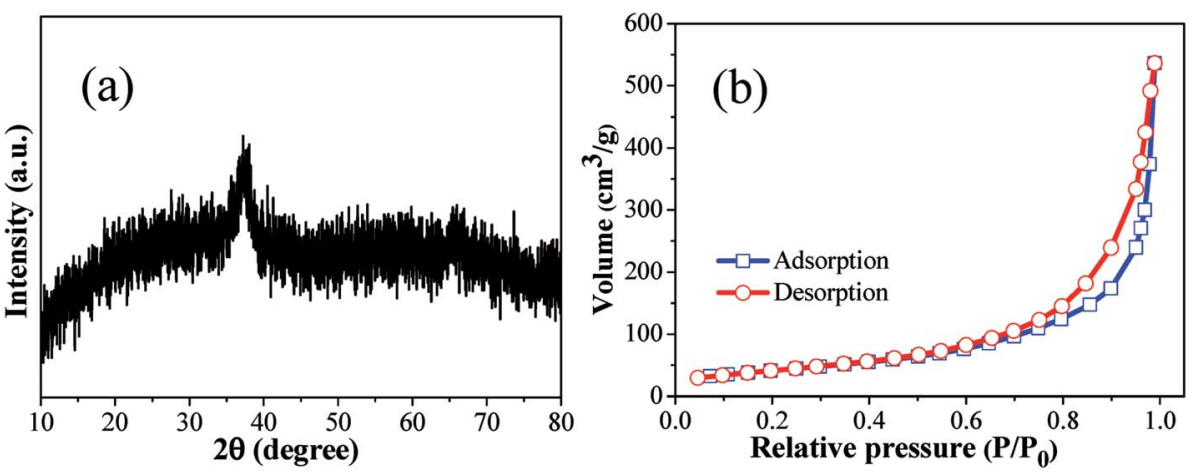

Fig. 2 XRD patterns (a) and $\mathrm{N}_{2}$ adsorption-desorption isotherm (b) of as-prepared copper-manganese composite oxide.

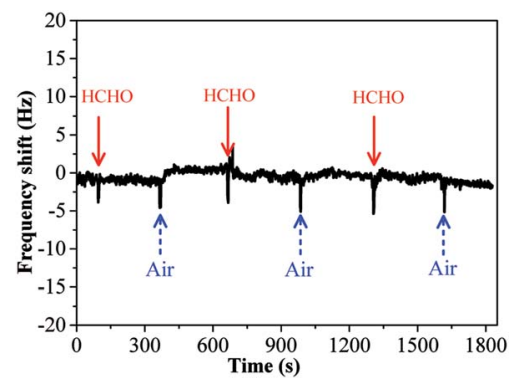

Fig. 3 Profiles of frequency shift of unmodified silver-coated QCM resonator upon exposure to air containing $1.7 \mathrm{ppm} \mathrm{HCHO}$ at $20^{\circ} \mathrm{C}$.

QCM resonator $\left(2.09 \mathrm{~Hz}(\mu \mathrm{g} \mathrm{ppm})^{-1}\right){ }^{18}$ When the testing chamber was flushed by air, the frequency shift was basically recovered. Fig. 5 shows profiles of frequency shift of as-prepared copper-manganese composite oxide functionalized QCM resonator upon exposure to air containing $1.7 \mathrm{ppm} \mathrm{HCHO}$ at $20{ }^{\circ} \mathrm{C}$ in three continuous cycles. The response curves are similar for these three continuous cycles with nearly no changes in response, response time and recovery time, indicating good reproducibility of the copper-manganese composite oxide functionalized QCM resonator.

In order to test its long time stability, the copper-manganese composite oxide functionalized QCM was also tested 10 days, 30 days and 60 days, respectively, after fabrication (coating amount: $25 \mu \mathrm{g})$. As shown in Fig. 6, the frequency shifts taken at

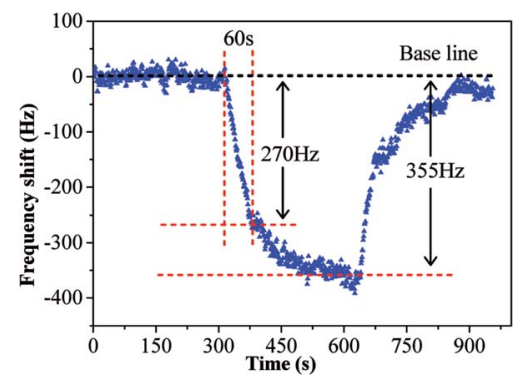

Fig. 4 Profile of frequency shift of as-prepared copper-manganese composite oxide functionalized QCM resonator upon exposure to air containing $1.7 \mathrm{ppm} \mathrm{HCHO}$ at $20^{\circ} \mathrm{C}$ (coating amount: $25 \mu \mathrm{g}$ ).

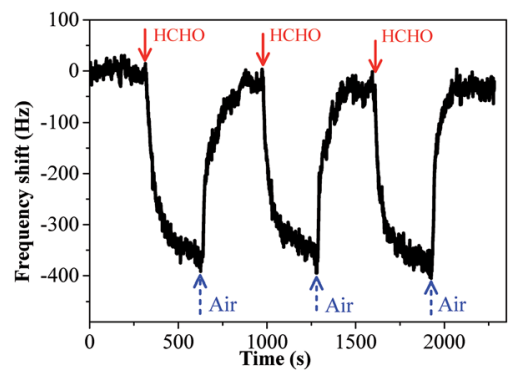

Fig. 5 Profiles of frequency shift of as-prepared copper-manganese composite oxide functionalized QCM resonator upon exposure to air containing $1.7 \mathrm{ppm} \mathrm{HCHO}$ at $20^{\circ} \mathrm{C}$ in three continuous cycles (coating amount: $25 \mu \mathrm{g}$ ).

$60 \mathrm{~s}$ after exposure to $\mathrm{HCHO}$ were $-276 \pm 5 \mathrm{~Hz}$ (10 days), -280 $\pm 4 \mathrm{~Hz}$ (30 days) and $-265 \pm 5 \mathrm{~Hz}$ (60 days), respectively, and the frequency shifts taken at equilibrium state after exposure to $\mathrm{HCHO}$ were $-360 \pm 7 \mathrm{~Hz}$ (10 days), $-362 \pm 5 \mathrm{~Hz}$ (30 days) and $-353 \pm 6 \mathrm{~Hz}$ (60 days), respectively. No significant changes were observed either for the sensing profile, indicating that the sensing characteristics of copper-manganese composite oxide functionalized QCM resonator is quite stable in an extended period of time. Fig. 7 displays the response curves of coppermanganese composite oxide functionalized QCM resonator (coating amount: $25 \mu \mathrm{g}$ ) upon exposure to $\mathrm{HCHO}$ of varied

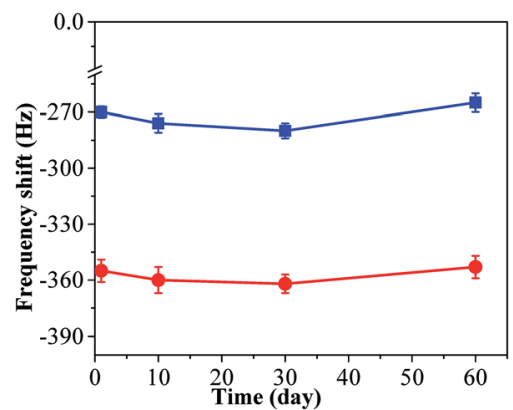

Fig. 6 Frequency shifts taken at $60 \mathrm{~s}$ (blue square) and saturation state (red dot) after exposure to air containing $1.7 \mathrm{ppm} \mathrm{HCHO}$ at $20{ }^{\circ} \mathrm{C}$ (coating amount: $25 \mu \mathrm{g}$ ) 0, 10, 30 and 60 days, respectively, after fabrication. 


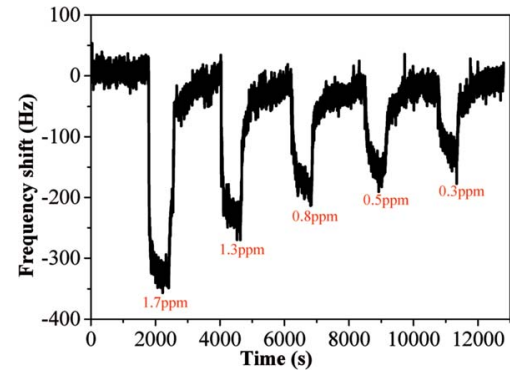

Fig. 7 Profiles of frequency shift of as-prepared copper-manganese composite oxide functionalized QCM resonator upon exposure to $\mathrm{HCHO}$ gas of varied concentrations at $20^{\circ} \mathrm{C}$ (coating amount: $25 \mu \mathrm{g}$ ).

concentrations. When HCHO of $1.7 \mathrm{ppm}, 1.3 \mathrm{ppm}, 0.8 \mathrm{ppm}$, $0.5 \mathrm{ppm}$ and $0.3 \mathrm{ppm}$, respectively, were introduced into the testing chamber, the frequency shifts of copper-manganese composite oxide functionalized QCM resonator was recorded, and all responses were similar in shape, and the response of QCM resonator decreases in proportion to the decrease of HCHO concentration. The frequency shifts $60 \mathrm{~s}$ after exposure to $\mathrm{HCHO}$ were plotted against the corresponding $\mathrm{HCHO}$ concentrations, giving a linear relationship in the concentration range of $0-1.7 \mathrm{ppm}$. A linear equation was derived as follows (Fig. 8):

$$
\Delta F=-167 c+0.5 r=0.97
$$

where $\Delta \mathrm{F}$ is the frequency shift $60 \mathrm{~s}$ after exposure to HCHO $(\mathrm{Hz}), c$ is the HCHO concentration (ppm), $r$ is regression coefficient. The liner equation could be used for quantitative analysis of $\mathrm{HCHO}$ based on the copper-manganese composite oxide functionalized QCM resonator. Selectivity is an important factor for sensors in practical applications. It was investigated by exposing the copper-manganese composite oxide functionalized QCM resonator to a variety of common volatile chemicals (ethanol, toluene, para-xylene and acetone) under otherwise identical conditions for formaldehyde. Fig. 9 shows the frequency shifts of copper-manganese composite oxide functionalized QCM resonator upon exposure to HCHO (1.7 ppm), ethanol (0.3 ppm), toluene (0.2 ppm), para-xylene

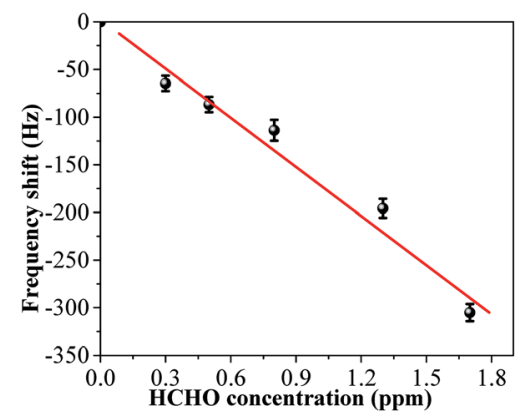

Fig. 8 Linear relationship between response and $\mathrm{HCHO}$ concentration at $20^{\circ} \mathrm{C}$ (coating amount: $25 \mu \mathrm{g}$ ). Frequency shifts taken $60 \mathrm{~s}$ after exposure to $\mathrm{HCHO}$ were used as responses.

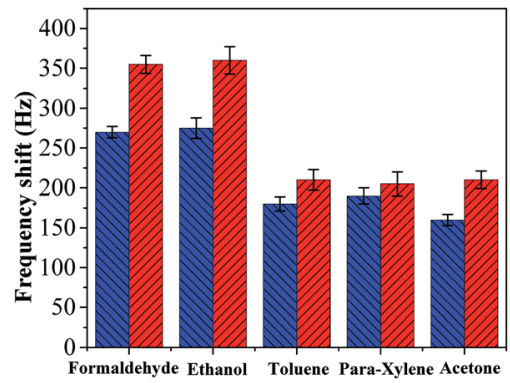

Fig. 9 Frequency shifts of as-prepared copper-manganese composite oxide functionalized QCM resonator upon exposure to $\mathrm{HCHO}$, ethanol, toluene, para-xylene and acetone (frequency shifts at $60 \mathrm{~s}$ : blue column; frequency shifts at equilibrium state: red column).

(0.5 ppm) and acetone (1.4 ppm) at $60 \mathrm{~s}$ (blue column) and equilibrium state (red column), respectively. The coppermanganese composite oxide functionalized QCM resonator shows very near responses to formaldehyde and ethanol. Thus, ethanol may be an interference factor in the detection of formaldehyde for the copper-manganese composite oxide functionalized QCM resonator.

The interaction that occurred between the mass sensitive chemical sensor surface and vaporized analyte molecules can be attributed to the sorption mechanism of gas molecules on the surface. ${ }^{25,26}$ The sorption corresponds to condensation of vaporized molecules on the surface by intermolecular forces, such as hydrogen bonding and van-der-Waals interactions. On the basis of analyses of our experimental results, the sensing mechanism of copper-manganese composite oxide functionalized QCM resonator to $\mathrm{HCHO}$ belongs to the sorption process. There are many oxygen atoms on the surface of coppermanganese composite oxide. ${ }^{27,28}$ As shown in Scheme 1, when $\mathrm{HCHO}$ was introduced into the testing chamber, it was adsorbed on the oxygen of copper-manganese composite oxide via hydrogen bonding, the total mass on QCM resonator increased, and thus a negative frequency shift was observed according to the Sauerbrey equation. When the testing chamber was flushed by air, the adsorbed HCHO was desorbed from the coppermanganese composite oxide, and thus the frequency shift recovered. These processes are reversible, which brings the excellent reproducibility of copper-manganese composite oxide functionalized QCM resonator. Similar interactions occur between copper-manganese composite oxide and ethanol or acetone, and van-der-Waals interactions with toluene or paraxylene. The copper-manganese composite oxide functionalized QCM resonator also showed similar responses to these analytes. Thus, these analytes could be an interference factor in the detection of formaldehyde for the copper-manganese composite oxide functionalized QCM resonator in real sample analysis. Even so, the copper-manganese composite oxide functionalized QCM resonator could be used for quantitative analysis or concentration monitoring of $\mathrm{HCHO}$ in a formaldehyde environment in real time because of the linear equation between the response of QCM resonator and $\mathrm{HCHO}$ concentration. 

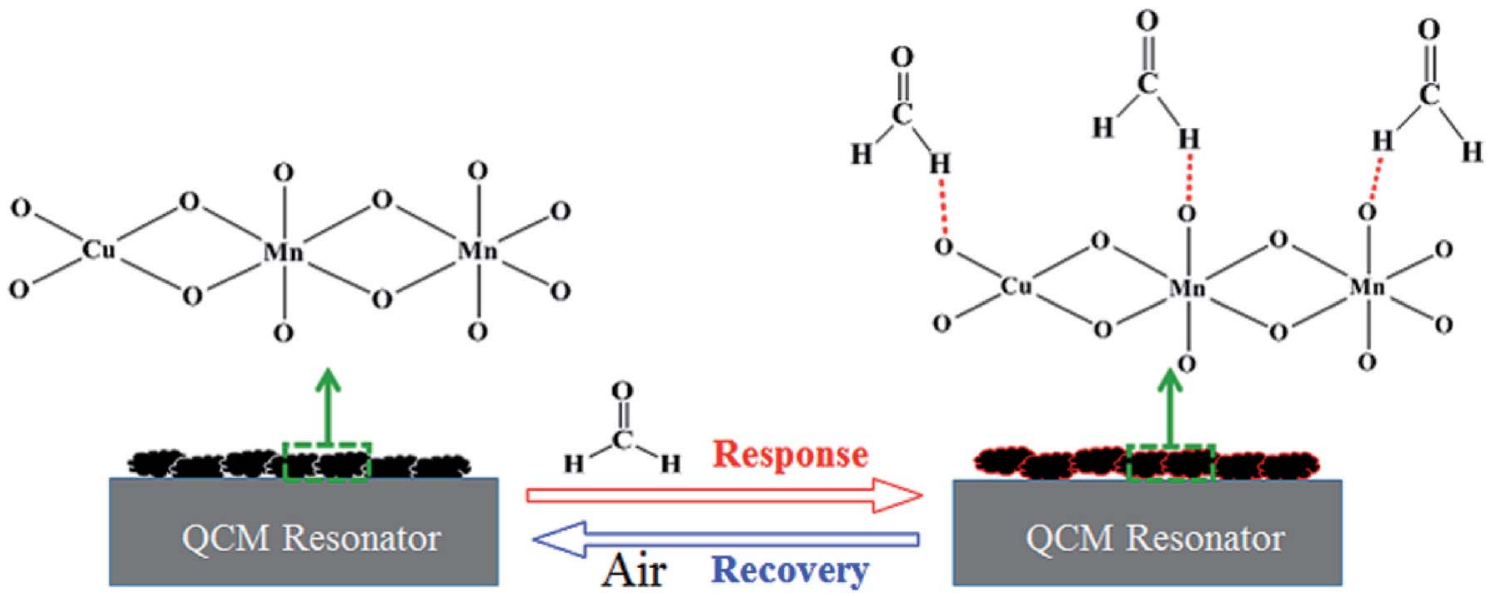

Scheme 1 Schematic illustration of the process on as-prepared copper-manganese composite oxide functionalized QCM resonator.

\section{Conclusion}

Copper-manganese composite oxide functionalized QCM resonators were fabricated and explored for HCHO sensing. The copper-manganese composite oxide functionalized QCM resonators had a significant response to HCHO. The frequency shift of copper-manganese composite oxide functionalized QCM resonator with $25 \mu \mathrm{g}$ coating amount reached $-270 \mathrm{~Hz}$ in $60 \mathrm{~s}$. Neither for the response nor for the sensing profile were observed significant changes after 60 days, indicating that the sensing characteristics of copper-manganese composite oxide functionalized QCM resonator is stable. In addition, the copper-manganese composite oxide functionalized QCM resonator could be used for quantitative analysis or concentration monitoring of $\mathrm{HCHO}$ in a formaldehyde environment in real time because of the linear equation between the response of QCM resonator and $\mathrm{HCHO}$ concentration.

\section{Conflicts of interest}

There are no conflicts of interest to declare.

\section{Acknowledgements}

The work described here was supported by the National Natural Science Foundation of China (Grant No. 21607158, 21271177, 21571182), the National Key Research and Development Program of China (Grant No. 2017YFA0207102) and Technical Institute of Physics and Chemistry, CAS.

\section{References}

1 T. Salthammer, S. Mentese and R. Marutzky, Chem. Rev., 2010, 110, 2536-2572.

2 C. Zhang, F. Liu, Y. Zhai, H. Ariga, N. Yi, Y. Liu, K. Asakura, M. Flytzani and H. He, Angew. Chem., Int. Ed., 2012, 51, 96289632.

3 L. Feng, C. J. Musto and K. S. Suslick, J. Am. Chem. Soc., 2010, 132, 4046-4047.
4 R. Xing, L. Xu, Y. Zhu, J. Song, W. Qin, Q. Dai, D. Liu and H. Song, Sens. Actuators, B, 2013, 188, 235-241.

5 L. Han, D. Wang, Y. Lu, T. Jiang, B. Liu and Y. Lin, J. Phys. Chem. C, 2011, 115, 22939-22944.

6 C. Zhang, X. Wang, J. Lin, B. Ding, J. Yu and N. Pan, Sens. Actuators, B, 2011, 152, 316-323.

7 H. Tian, H. Fan, M. Li and L. Ma, ACS Sens., 2016, 1, 243250.

8 D. Yan, P. Xu, Q. Xiang, H. Mou, J. Xu, W. Wen, X. Li and Y. Zhang, J. Mater. Chem. A, 2016, 4, 3487-3493.

9 Z. Ye, H. Tai, T. Xie, Z. Yuan, C. Liu and Y. Jiang, Sens. Actuators, B, 2016, 223, 149-156.

10 M. Hussain, K. Kotova and P. Lieberzeit, Sensors, 2016, 16, 1011.

11 K. A. Marx, Biomacromolecules, 2003, 4, 1099-1120.

12 J. Wang, Z. Zhu and H. Ma, Anal. Chem., 2013, 85, 20962101.

13 Y. Yao and Y. Xue, Sens. Actuators, B, 2015, 211, 52-58.

14 H. Tai, Y. Zhen, C. Liu, Z. Ye, G. Xie, X. Du and Y. Jiang, Sens. Actuators, B, 2016, 230, 501-509.

15 Z. Yuan, H. Tai, Z. Ye, C. Liu, G. Xie, X. Du and Y. Jiang, Sens. Actuators, B, 2016, 234, 145-154.

16 M. Yang and J. He, J. Colloid Interface Sci., 2012, 368, 41-48. 17 M. Yang, J. He, M. Hu, X. Hu, C. Yan and Z. Cheng, Sens. Actuators, B, 2015, 213, 59-64.

18 M. Yang and J. He, Sens. Actuators, B, 2016, 228, 486-490.

19 Z. Liu, J. Zhu, J. Li, L. Ma and S. I. Woo, ACS Appl. Mater. Interfaces, 2014, 6, 14500-14508.

20 J. A. Pérez-Omil, J. J. Delgado, W. Ouahbi, A. B. Hungría, N. Browning, M. A. Cauqui, J. M. Rodríguez-Izquierdo and J. J. Calvino, J. Phys. Chem. C, 2010, 114, 8981-8991.

21 G. Zhang, J. Qu, H. Liu, R. Liu and G. Li, Environ. Sci. Technol., 2007, 41, 4613-4619.

22 G. K. Reddy, J. He, S. W. Thiel, N. G. Pinto and P. G. Smirniotis, J. Phys. Chem. C, 2015, 119, 8634-8644.

23 S. M. Vickers, R. Gholami, K. J. Smith and M. J. MacLachlan, ACS Appl. Mater. Interfaces, 2015, 7, 11460-11466.

24 S. Ding, F. Liu, X. Shi, K. Liu, Z. Lian, L. Xie and H. He, ACS Appl. Mater. Interfaces, 2015, 7, 9497-9506. 
25 S. Öztürk, A. Kösemen, Z. A. Kösemen, N. Kılınç, Z. Z. Öztürk and M. Penza, Sens. Actuators, B, 2016, 222, 280-289.

26 S. Lee, N. Takahara, S. Korposh, D. Yang, K. Toko and T. Kunitake, Anal. Chem., 2010, 82, 2228-2236.
27 T. Liu, Y. Yao, L. Wei, Z. Shi, L. Han, H. Yuan, B. Li, L. Dong, F. Wang and C. Sun, J. Phys. Chem. C, 2017, 121, 1275712770.

28 J. Li, P. Zhang, J. Wang and M. Wang, J. Phys. Chem. C, 2016, 120, 24121-24129. 